\title{
Interaction between Quaternary Ammonium Ions and Dipeptides: Positive Anion Allosteric Effect
}

\author{
Kazuaki Ito, * Kayo Nagase, Naoya Morohashi, and Yoshihiro Ohbа \\ Department of Chemistry and Chemical Engineering, Faculty of Engineering, Yamagata University; 4-3-16 Jyonan, \\ Yonezawa 992-8510, Japan. Received June 25, 2004; accepted October 1, 2004
}

\begin{abstract}
The binding properties of dipeptides possessing aromatic residues towards quaternary ammonium ions have been investigated by ${ }^{1} \mathrm{H}$-NMR spectroscopy. The intermolecular hydrogen bonding between exchangeable protons $(\mathrm{OH}$ and $\mathrm{NH}$ ) of aromatic residues of dipeptides and the counter anion of ammonium ion is the primary force. After the formation of the intermolecular hydrogen bonding, two aromatic residues of dipeptides can provide $\pi$-base cavity to interact with the quaternary ammonium moiety.
\end{abstract}

Key words cation $-\pi$ interaction; hydrogen bonding; allosteric effect; quaternary ammonium ion; peptide

Noncovalent interactions are of fundamental importance in determining the highly dimensional structures and fundamental properties of molecular systems in biology, chemistry, and materials sciences. Relatively strong non-covalent bonding such as salt bridge and hydrogen bonding has been extensively investigated. In contrast, weak noncovalent bonding such as $\pi-\pi, \mathrm{CH}-\pi$ and cation- $\pi$ interaction is now known to play important roles in the stabilization of the complexes ${ }^{1-3)}$ but is not well understood, because the weak noncovalent bond is usually cancelled behind the strong noncovalent bonding. However, there is much attention on cation $-\pi$ interaction in a biological event such as recognition of biological relevant quaternary ammonium ions, for example, the neurotransmitter acetylcholine, by receptors and enzyme. ${ }^{4)}$ Therefore, several research groups have devoted considerable effort to the synthesis of receptor molecules to investigate binding properties of quaternary ammonium cations. $^{5-10)}$

In spite of many reports of synthetic receptors for binding quaternary ammonium ions, we are unaware of any on acyclic compounds acting as a receptor. ${ }^{11)}$ Recently, we reported a study on the recognition of quaternary ammonium ion using acyclic phenol-formaldehyde dimer as a receptor, and found that quaternary ammonium cation is entrapped in the $\pi$ cavity which is constructed of two phenol units; its counter ion participates in the recognition process by coordination via hydrogen bonding of the two hydroxyl groups. ${ }^{12)}$

As part of this study, we investigated the interaction between quaternary ammonium ions and dipeptides having the aromatic amino acid residues tyrosine and tryptophane, which have exchangeable protons $(\mathrm{OH}$ and $\mathrm{NH})$ and aromatic surfaces.

Dipeptides (1) were prepared in good yield by the condensation reactions of $N$-Boc L-amino acid with L-amino acid methyl ester monohydrochloride in the presence of $N$-methyl morphorine in $\mathrm{CHCl}_{3}$ using DCC (1,3-dicyclohexylcarbodiimide) as a condensation reagent according to the literature (Fig. 1). ${ }^{13)}$

The interaction behavior of dipeptides (1) and quaternary ammonium ions (2) was studied by using ${ }^{1} \mathrm{H}-\mathrm{NMR}$ spectroscopy at $20^{\circ} \mathrm{C}$. When benzyl trimethyl ammonium chloride (2a) was added into a $\mathrm{CDCl}_{3}$ solution of Boc-Tyr-TyrOMe (1a) at the ratio of $\mathbf{1 a}: \mathbf{2 a}=1: 1([\mathbf{1}]=[\mathbf{2}]=10 \mathrm{~mm})$, all peaks of 2a moved to a higher field due to the ring current ef- fect of the aromatic rings of 1a during formation of the complex as shown in Fig. 2. Especially, higher induced chemical shifts of the $\mathrm{N}^{+}-\mathrm{CH}_{2}$ and $\mathrm{N}^{+}-\mathrm{CH}_{3}$ protons of $2 \mathrm{a}$ were observed, suggesting that the ammonium moiety is located close to the aromatic surface of $\mathbf{1 a} .^{5-12)}$ The same phenomenon was also observed in the mixture of Boc-Trp-Trp-OMe (1b) and 2a in $\mathrm{CDCl}_{3}$. In contrast, the chemical shifts of 2a scarcely changed in the presence of Boc-Phe-Phe-OMe (1c), indicating that no complexation occurs between 1c and $\mathbf{2 a}$. Although Boc-Tyr-Phe-OMe (1d) and Boc-Trp-Phe-OMe (1e) having a phenol or an indole group can interact with ammonium ion (2a), the induced chemical shifts are smaller than those of $\mathbf{1 a}$ and $\mathbf{1 b}$. We also observed a similar induced chemical shift pattern in the complexation of peptides (1) with other quaternary ammonium salts $(\mathbf{2 b}, \mathbf{c})$ as shown in Table 1.

Interestingly, the induced chemical shifts were dramatically reduced by the replacement of counter anion of ammonium from chloride (2a) to iodide (2d). Another important observation was that the ${ }^{1} \mathrm{H}-\mathrm{NMR}$ signals for exchangeable protons $(\mathrm{NH}$ and $\mathrm{OH})$ of aromatic amino acid residues of $\mathbf{1}$ were considerably downfield-shifted and extensively broadened upon addition of $2 .^{12,14)}$ These results could be explained by hypothesizing an important role for the anion that interacts with the $\mathrm{OH}$ or $\mathrm{NH}$ groups of $\mathbf{1}$. This hypothesis is supported by the lack of efficiency shown by Boc-Phe-PheOMe (1c) of which the absence of the exchangeable proton prevents any participation of the anion in the binding event.

We estimated the stoichiometry of the complex (1-2) using the Job plot method. ${ }^{15)}$ The $1: 1$ stoichiometry of the complexes (1-2) was confirmed by the plot, which contains a maximum at the molar ratio of 0.5 in all cases (Fig. 3). The binding affinities of peptide (1) to quaternary ammonium ions (2) were determined by nonlinear least-squares fitting method of the saturation curves obtained from ${ }^{1} \mathrm{H}-\mathrm{NMR}$ titration (Fig. 4). ${ }^{16)}$ During the titration by varying concentrations of 1 and 2 in $\mathrm{CDCl}_{3}$, the signals for the protons of ammonium moiety of 2 are gradually upfield-shifted. ${ }^{17)}$ The obtained association constants $\left(K_{\mathrm{a}}\right)$ of the complexes (1-2) indicated that $\mathbf{2}$ was bound by tyrosine peptides (1a, d) more efficiently than tryptophane peptides $(\mathbf{1 b}, \mathbf{e})$. It is also clear that the association constants are strongly dependent on the nature of the anion of 2. Although Boc-Tyr-Tyr-OMe (1a) and Boc-Tyr-Phe-OMe (1d) had similar association constants, the 

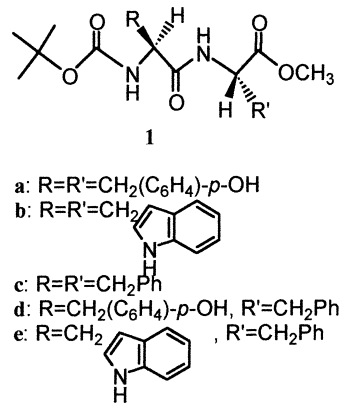

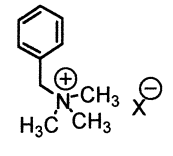

2a: $\mathrm{R}=\mathrm{H}, \mathrm{X}=\mathrm{Cl}$ 2a: $: R=H, X=C l$
$R=H$

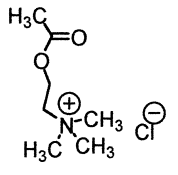

2b

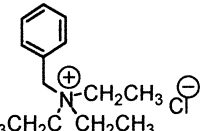

$2 c$

Fig. 1

Table 1. Chemical Shift Changes $(\Delta \delta)$ in $\mathbf{2}$ Induced by Added $\mathbf{1}^{a}$

Ammonium ion (2a)/[ppm]

\begin{tabular}{|c|c|c|c|c|c|c|c|c|c|c|}
\hline \multirow{2}{*}{ Peptide } & \multicolumn{2}{|c|}{$\mathrm{N}\left(\mathrm{CH}_{3}\right)_{3}$} & \multicolumn{2}{|c|}{$\mathrm{NCH}_{2}$} & \multicolumn{2}{|c|}{$o$-proton } & \multicolumn{2}{|c|}{$m$-proton } & \multicolumn{2}{|c|}{$p$-proton } \\
\hline & $\delta$ & $\Delta \delta$ & $\delta$ & $\Delta \delta$ & $\delta$ & $\Delta \delta$ & $\delta$ & $\Delta \delta$ & $\delta$ & $\Delta \delta$ \\
\hline None & 3.42 & - & 5.04 & - & 7.66 & - & 7.49 & - & 7.52 & - \\
\hline $1 \mathbf{a}$ & 3.17 & -0.25 & 4.68 & -0.36 & 7.51 & -0.15 & 7.43 & -0.06 & 7.49 & -0.03 \\
\hline $1 b$ & 3.14 & -0.28 & 4.73 & -0.31 & 7.51 & -0.15 & 7.44 & -0.05 & 7.49 & -0.03 \\
\hline 1c & 3.42 & 0.00 & 5.04 & 0.00 & 7.66 & 0.00 & 7.49 & 0.00 & 7.52 & 0.00 \\
\hline 1d & 3.34 & -0.08 & 4.91 & -0.13 & 7.62 & -0.04 & 7.48 & -0.01 & 7.51 & -0.01 \\
\hline $1 \mathrm{e}$ & 3.38 & -0.04 & 4.99 & -0.05 & 7.63 & -0.03 & 7.48 & -0.01 & 7.52 & 0.00 \\
\hline
\end{tabular}

Ammonium ion $(\mathbf{2 b}) /[\mathrm{ppm}]$

\begin{tabular}{|c|c|c|c|c|c|c|c|c|}
\hline \multirow{2}{*}{ Peptide } & \multicolumn{2}{|c|}{$\mathrm{N}\left(\mathrm{CH}_{3}\right)_{3}$} & \multicolumn{2}{|c|}{$\mathrm{NCH}_{2}$} & \multicolumn{2}{|c|}{$\mathrm{OCH}_{2}$} & \multicolumn{2}{|c|}{$\mathrm{COCH}_{2}$} \\
\hline & $\delta$ & $\Delta \delta$ & $\delta$ & $\Delta \delta$ & $\delta$ & $\Delta \delta$ & $\delta$ & $\Delta \delta$ \\
\hline None & 3.57 & - & 4.57 & - & 4.19 & - & 2.13 & - \\
\hline $1 \mathbf{a}$ & 3.28 & -0.29 & 4.42 & -0.15 & 3.85 & -0.34 & 2.05 & -0.08 \\
\hline $1 b$ & 3.28 & -0.29 & 4.39 & -0.18 & 3.86 & -0.33 & 2.13 & -0.05 \\
\hline $1 c$ & 3.55 & 0.02 & 4.57 & 0.00 & 4.17 & 0.02 & 2.10 & 0.00 \\
\hline $1 d$ & 3.48 & -0.13 & 4.48 & -0.09 & 4.04 & -0.15 & 2.11 & -0.03 \\
\hline 1e & 3.42 & -0.09 & 4.51 & -0.06 & 4.09 & -0.10 & 2.11 & -0.02 \\
\hline
\end{tabular}

Ammonium ion $(\mathbf{2 c}) /[\mathrm{ppm}]$

\begin{tabular}{|c|c|c|c|c|c|c|c|c|c|c|c|c|}
\hline \multirow{2}{*}{ Peptide } & \multicolumn{2}{|c|}{$\left(\mathrm{CH}_{3}\right)_{3}$} & \multicolumn{2}{|c|}{$\left(\mathrm{CH}_{2}\right)_{3}$} & \multicolumn{2}{|c|}{$\mathrm{NCH}_{2}$} & \multicolumn{2}{|c|}{$o$-proton } & \multicolumn{2}{|c|}{$m$-proton } & \multicolumn{2}{|c|}{$p$-proton } \\
\hline & $\delta$ & $\Delta \delta$ & $\delta$ & $\Delta \delta$ & $\delta$ & $\Delta \delta$ & $\delta$ & $\Delta \delta$ & $\delta$ & $\Delta \delta$ & $\delta$ & $\Delta \delta$ \\
\hline None & 1.48 & - & 3.49 & - & 4.85 & - & 7.57 & - & 7.46 & - & 7.50 & - \\
\hline $1 \mathrm{a}$ & 1.42 & -0.06 & 3.32 & -0.17 & 4.58 & -0.27 & 7.46 & -0.11 & 7.44 & -0.02 & 7.50 & 0.00 \\
\hline $1 b$ & 1.36 & -0.12 & 3.29 & -0.20 & 4.60 & -0.25 & b) & & b) & & 7.50 & 0.00 \\
\hline $1 \mathrm{c}$ & 1.48 & 0.00 & 3.49 & 0.00 & 4.85 & 0.00 & 7.57 & 0.00 & 7.46 & 0.00 & 7.50 & 0.00 \\
\hline 1d & 1.46 & -0.02 & 3.45 & -0.02 & 4.79 & -0.06 & 7.54 & -0.03 & 7.45 & -0.01 & 7.50 & 0.00 \\
\hline $1 \mathrm{e}$ & 1.47 & -0.01 & 3.46 & -0.03 & 4.81 & -0.04 & 7.55 & -0.02 & 7.45 & -0.01 & 7.50 & 0.00 \\
\hline
\end{tabular}

Ammonium ion $(\mathbf{2 d}) /[\mathrm{ppm}]$

\begin{tabular}{|c|c|c|c|c|c|c|c|c|c|c|}
\hline \multirow{2}{*}{ Peptide } & \multicolumn{2}{|c|}{$\mathrm{N}\left(\mathrm{CH}_{3}\right)_{3}$} & \multicolumn{2}{|c|}{$\mathrm{NCH}_{2}$} & \multicolumn{2}{|c|}{$o$-proton } & \multicolumn{2}{|c|}{$m$-proton } & \multicolumn{2}{|c|}{$p$-proton } \\
\hline & $\delta$ & $\Delta \delta$ & $\delta$ & $\Delta \delta$ & $\delta$ & $\Delta \delta$ & $\delta$ & $\Delta \delta$ & $\delta$ & $\Delta \delta$ \\
\hline None & 3.38 & - & 4.90 & - & 7.63 & - & 7.53 & - & 7.53 & - \\
\hline $1 \mathbf{a}$ & 3.30 & -0.08 & 4.78 & -0.12 & 7.57 & -0.06 & 7.51 & -0.02 & 7.52 & -0.01 \\
\hline $1 b$ & 3.31 & -0.07 & 4.82 & -0.08 & 7.59 & -0.04 & 7.51 & -0.02 & 7.52 & -0.01 \\
\hline 1c & 3.38 & 0.00 & 4.90 & -0.00 & 7.63 & 0.00 & 7.53 & 0.00 & 7.53 & 0.00 \\
\hline 1d & 3.34 & -0.04 & 4.83 & -0.07 & 7.61 & -0.02 & 7.52 & -0.01 & 7.52 & -0.01 \\
\hline $1 \mathrm{e}$ & 3.35 & -0.03 & 4.87 & -0.03 & 7.63 & 0.00 & 7.53 & 0.00 & 7.53 & 0.00 \\
\hline
\end{tabular}

a) At $20^{\circ} \mathrm{C}$ in $\mathrm{CDCl}_{3},[\mathbf{1}]=[\mathbf{2}]=10 \mathrm{~mm}$, - denotes the shift to higher magnetic field. b) The aromatic protons of $\mathbf{2 d}$ are overlapped with the protons of $\mathbf{1 b}$. 


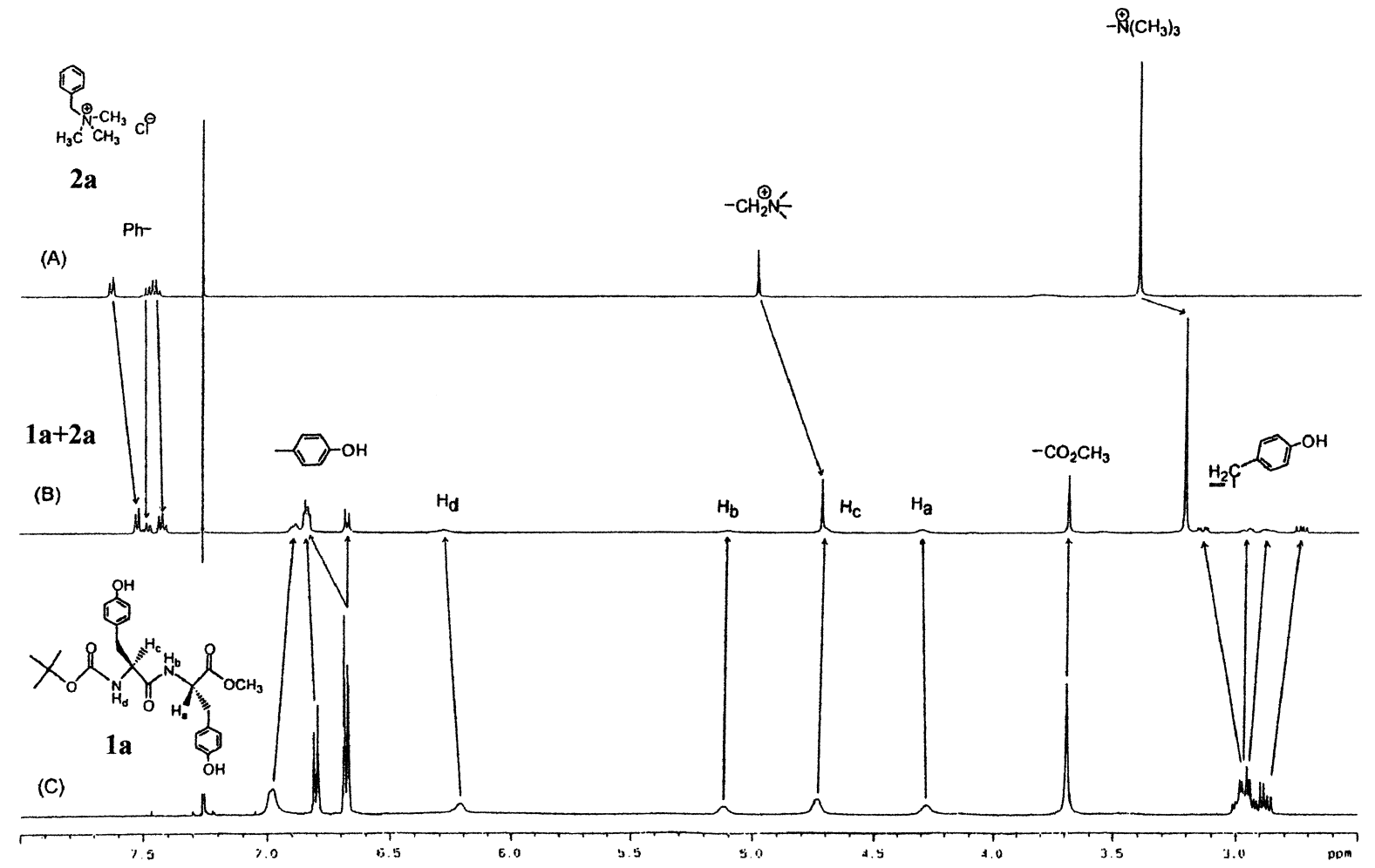

Fig. 2. Partial ${ }^{1} \mathrm{H}-\mathrm{NMR}$ Spectra for $\mathbf{2 a}(\mathrm{A}), \mathbf{1 a}+\mathbf{2 a}(\mathrm{B}), \mathbf{1 a}(\mathrm{C})$ at $20^{\circ} \mathrm{C}$ in $\mathrm{CDCl}_{3}$

$[\mathbf{1 a}]=[\mathbf{2 a}]=10 \mathrm{~mm}$.

Table 2. Association Constants $K_{\mathrm{a}}\left[\mathrm{M}^{-1}\right]$ for $1: 1$ Complexes Measured in $\mathrm{CDCl}_{3}$ of Quaternary Ammonium Salts $(\mathbf{2 a}-\mathbf{d})$ with Dipeptides $(\mathbf{1 a}-\mathbf{e})$ at $20^{\circ} \mathrm{C}$

\begin{tabular}{ccccc}
\hline \hline \multirow{2}{*}{ Dipeptide } & \multicolumn{4}{c}{ Ammonium ions } \\
\cline { 2 - 5 } & $\mathbf{2 a}$ & $\mathbf{2 b}$ & $\mathbf{2 c}$ & $\mathbf{2 d}$ \\
\hline \multirow{2}{1\mathbf{a}}{} & $100 \pm 13$ & $130 \pm 3$ & $125 \pm 12$ & $22 \pm 1$ \\
$\mathbf{1 b}$ & $69 \pm 4$ & $80 \pm 9$ & $55 \pm 2$ & $10 \pm 1$ \\
$\mathbf{1 c}$ & $<1$ & $<1$ & $<1$ & $<1$ \\
$\mathbf{1 d}$ & $70 \pm 6$ & $87 \pm 8$ & $59 \pm 1$ & $13 \pm 1$ \\
$\mathbf{1 e}$ & $18 \pm 2$ & $30 \pm 2$ & $6 \pm 1$ & $2 \pm<1$ \\
& & & & \\
\end{tabular}

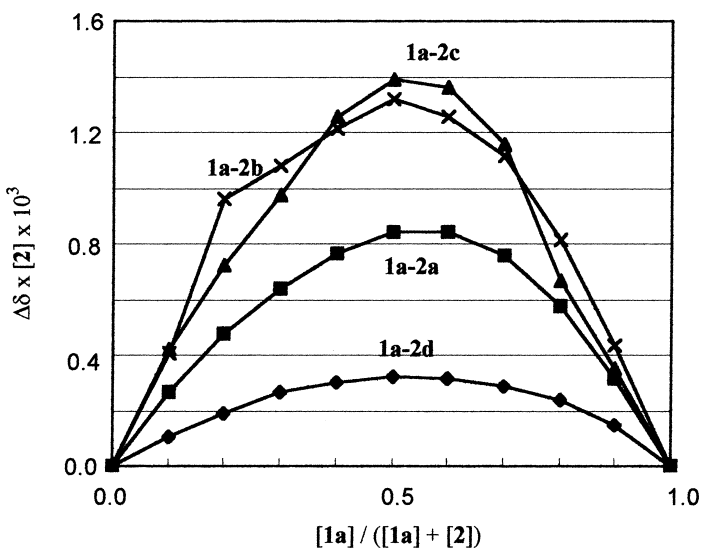

Fig. 3. Job Plots in the Complexation of 1a with 2

induced chemical shifts were quite different. Considering that association constants are mainly governed by the intermolecular hydrogen bonding, the large induced chemical

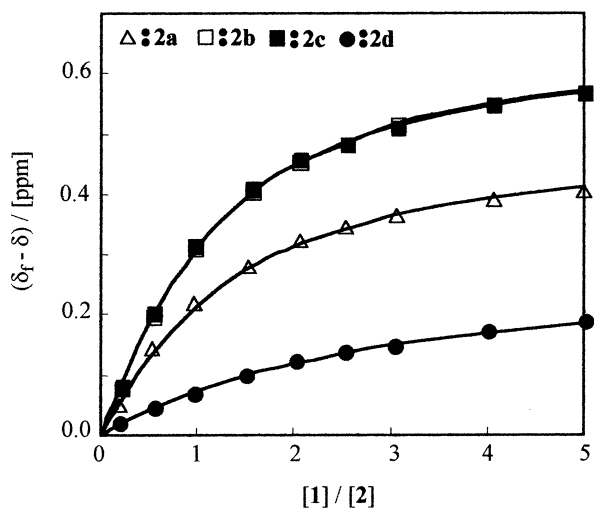

Fig. 4. ${ }^{1} \mathrm{H}-\mathrm{NMR}$ Titration of $\mathbf{1 a}$ with $\mathbf{2}$ in $\mathrm{CDCl}_{3}$ at $20^{\circ} \mathrm{C}$

$\left(\delta_{\mathrm{f}}-\delta\right)$ indicates a change in chemical shift of $\mathrm{N}^{+}\left(\mathrm{CH}_{3}\right)_{3}$ or $\mathrm{N}^{+} \mathrm{CH}_{2}$ protons of 2 as a result of added 1a. Points are experimental and curves are calculated by non-linear regression.

shifts observed in the complexes (1a-2) can be rationalized by assuming that cation $-\pi$ interaction exists. Similar large induced chemical shifts were also observed on the complexes of Boc-Trp-Trp-OMe (1b) with 2, implying the participation of the cation- $\pi$ interaction on binding 2 .

In order to elucidate the complex structure, we carried out a 2D NOE experiment (ROESY) using a 1:1 molar mixture of 1a and 2a $\left([\mathbf{1 a}]=[\mathbf{2 a}]=10 \mathrm{~mm}\right.$ in $\left.\mathrm{CDCl}_{3}\right)$. ROESY spectrum showed the cross peaks between $\mathrm{N}^{+}\left(\mathrm{CH}_{3}\right)_{3}$ of $\mathbf{2 a}$ and aryl protons of 1a, indicating that $\mathrm{N}^{+}\left(\mathrm{CH}_{3}\right)_{3}$ moiety of $\mathbf{2 a}$ is located close to the aryl surfaces of 1a (Fig. 5). This agrees with a situation where the $\mathrm{N}^{+}\left(\mathrm{CH}_{3}\right)_{3}$ moiety is inside the $\pi$ cavity created through the hydrogen bonding between anion and the peptide phenol groups. We also investigated whether 


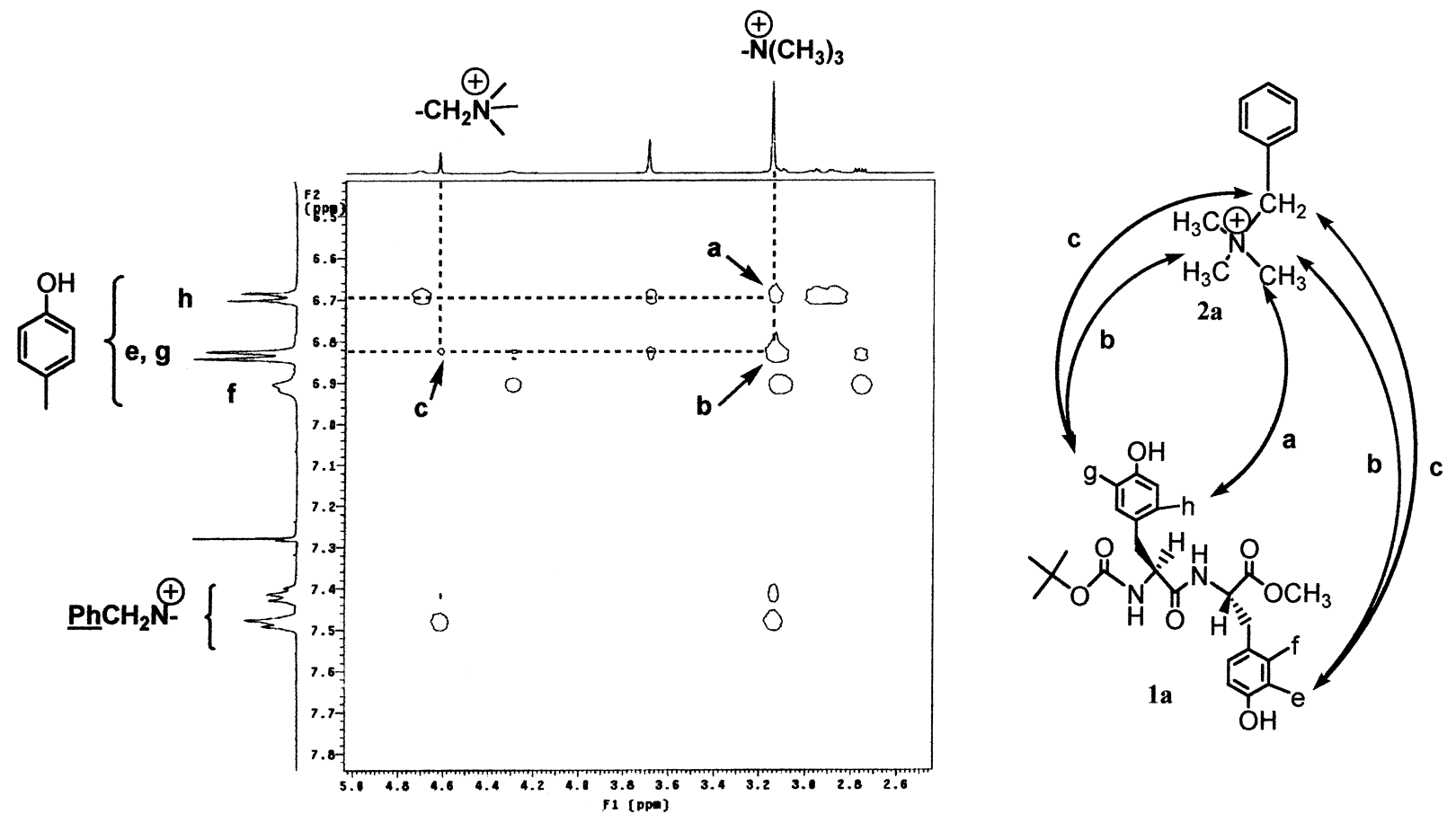

Fig. 5. ROESY ( $500 \mathrm{MHz}$, Mixing Time $=300 \mathrm{~ms}$ ) Spectrum for $\mathbf{1 a}$ and $\mathbf{2} \mathbf{b}$ in $\mathrm{CDCl}_{3}$ at $20^{\circ} \mathrm{C}$

$[\mathbf{1 a}]=[\mathbf{2 a}]=10 \mathrm{~mm}$.

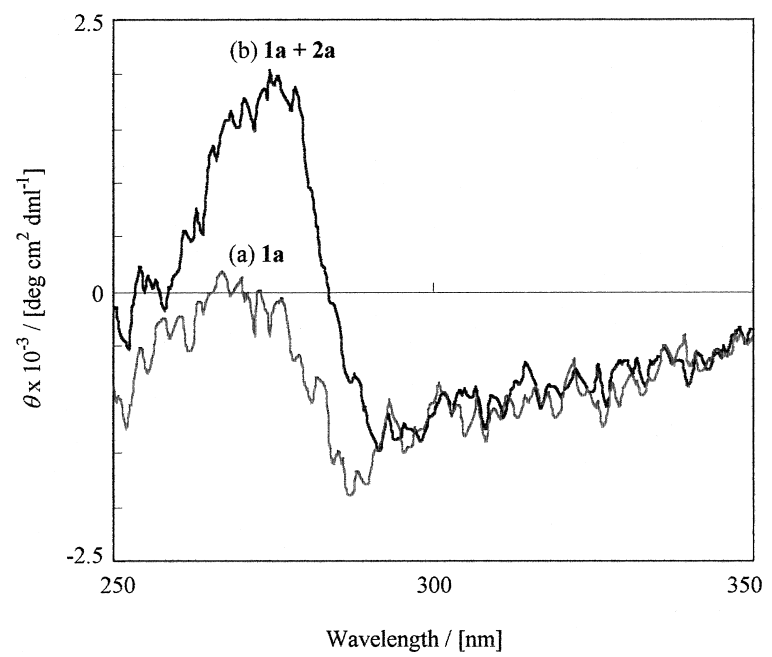

Fig. 6. CD Spectrum of 1a in the Absence (a) and in the Presence of 2a (b) in $\mathrm{CHCl}_{3}$ at $20^{\circ} \mathrm{C}$

$[\mathbf{1} \mathbf{a}]=[\mathbf{2 a}]=1.0 \mathrm{~mm}$.

the conformation of peptide (1a) changes upon interaction with ammonium ion (2) by CD (circular dichroism) spectroscopy, which is sensitive to conformational change. As shown in Fig. 6, CD spectral absorption of 1a was observed at $289 \mathrm{~nm}(\theta=-1870)$. Upon addition of $\mathbf{2 a}$, the absorption pattern was changed and the signal was observed at $291 \mathrm{~nm}$ $(\theta=-1460)$ and $275 \mathrm{~nm}(\theta=2040)$, supporting the above speculation. From these results we presented the plausible structure of the complex (1a-2) in Fig. 7.

In conclusion, we found that dipeptides constructed from the aromatic amino acid residues tyrosine and tryptophane can serve as a receptor of quaternary ammonium ions. The counter anion of ammonium ion participates in the recogni-

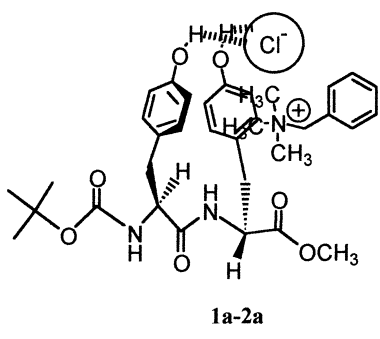

Fig. 7. Proposed Structure of Complex (1a-2a)

tion process by coordinating via hydrogen bonding with the $\mathrm{OH}$ or $\mathrm{NH}$ groups of tyrosine or tryptophane residue of dipeptides. As a result of the formation of the intermolecular hydrogen bonding, the two aromatic amino acid residues of dipeptides can provide a concave $\pi$-base to interact with the cation moiety of ammonium ions. This efficiency order $\left(\mathrm{Cl}^{-}>\mathrm{I}^{-}\right)$depends on the ability of anion to act as a hydrogen bonding acceptor, and supports the hypothesis of a positive anion allosteric effect.

\section{Experimental}

${ }^{1} \mathrm{H}$ - and ${ }^{13} \mathrm{C}-\mathrm{NMR}$ spectra were measured with Varian Mercury 200 and INOVA 500 spectrophotometers, using tetramethyl silane as an internal standard. CD spectra were obtained on a Jasco J-720 WI spectrophotometer. All amino acids were used in the L-form. Amino acids and benzyltrimethyl ammonium salts (2) were purchased from Tokyo Kasei Industries. Dipeptides (1) were prepared according to the literature. ${ }^{13)}$

General Procedure of the Synthesis of Dipeptides (1) To a solution of amino acid methyl ester monohydrochloride $(1 \mathrm{mmol}), N$-Boc amino acid $(1 \mathrm{mmol})$, and $N$-methyl morphorine $(1 \mathrm{mmol})$ in dry chloroform $(50 \mathrm{mmol})$ was added a solution of DCC $(1 \mathrm{mmol})$ in dry chloroform $(10 \mathrm{ml})$ over $20 \mathrm{~min}$ at $0^{\circ} \mathrm{C}$. After the addition was complete, the mixture was allowed to stir at room temperature for $12 \mathrm{~h}$. After removal of the precipitate by filtration, the filtrate was condensed. The residue was subjected to column chromatography on silica gel using hexane-ethyl acetate $1: 1$ as an eluent to give pure dipeptide (1) as colorless crystals. ${ }^{13)}$ 
Job Plot Method ${ }^{15)}$ The ${ }^{1} \mathrm{H}-\mathrm{NMR}$ sample solutions were made of $\mathbf{1 / 2}$ ratios under the condition that $[\mathbf{1}]+[\mathbf{2}]=10 \mathrm{~mm}$ in $\mathrm{CDCl}_{3}$, and [1] varies from $0 \mathrm{~mm}$ to $9 \mathrm{~mm}$ in $1 \mathrm{~mm}$ steps. The experimentally observed parameter is the ${ }^{1} \mathrm{H}-\mathrm{NMR}$ chemical shift $(\Delta \delta)$ of methyl groups $\left(\mathrm{N}^{+}-\left(\mathrm{CH}_{3}\right)_{3}\right)$ of 2 that is sensitive to complex formation. The data were plotted in the form $\Delta \delta \times[2]$ versus $[\mathbf{1}] /([\mathbf{1}]+[\mathbf{2}])$, and the position of the maximum indicates the stoichiometry of the complex.

${ }^{1}$ H-NMR Titration Experiment ${ }^{16)}$ Association constants $\left(K_{\mathrm{a}}\right)$ were obtained by ${ }^{1} \mathrm{H}-\mathrm{NMR}$ titration experiments, performed directly in the NMR tube using a micropipette to add known amounts $(0,10,50,100,150,200$, $300,400,500 \mu \mathrm{l}$ ) of peptide's (1) stock solution (concentration $=82.6 \mathrm{~mm}$ ) in $\mathrm{CDCl}_{3}$ to a solution of $2(700 \mu 1$, concentration $=11.9 \mathrm{~mm})$ in $\mathrm{CDCl}_{3}$. A $1: 1$ association of $\mathbf{1}$ and $\mathbf{2}$ was previously demonstrated, therefore, experimental data were fitted to the equation of the $1: 1$ binding isotherm by a nonlinear regression method. ${ }^{16)}$ All titration experiments were performed in $\mathrm{CDCl}_{3}$ at $20^{\circ} \mathrm{C}$ and $500 \mathrm{MHz}$.

\section{References and Notes}

1) Nishio M., "Introduction of Intermolecular Force in Organic Chemistry," Kodansha, Tokyo, 2000.

2) Dougherty D. A., Science, 271, 163-168 (1996).

3) Ma J. C., Dougherty D. A., Chem. Rev., 97, 1303-1324 (1997).

4) Sussman J. L., Harel M., Frolow F., Oefner C., Goldman A., Toker L., Silman I., Science, 253, 872-879 (1991).

5) Bartoli S., Roelens S., J. Am. Chem. Soc., 124, 8307-8315 (2002).
6) Arduni A., Giorgi G., Pochini A., Secchi A., Ugozzoli F., J. Org. Chem., 66, 8302-8308 (2001).

7) Arduini A., Pochini A., Secchi A., Eur. J. Org. Chem., 2325-2334 (2000).

8) Roelens S., Torriti R., J. Am. Chem. Soc., 120, 12443-12452 (1998).

9) Koh K. N., Araki K., Ikeda A., Otsuka H., Shinkai S., J. Am. Chem. Soc., 118, 755-758 (1996).

10) Garel L., Lozach B., Dutasta J.-P., Collet A., J. Am. Chem. Soc., 115, $11652-11653$ (1993).

11) Jeong K.-S., Hahn K.-M., Cho Y. L., Tetrahedron Lett., 39, 3779 3782 (1998).

12) Ito K., Miki H., Ohba Y., Yakugaku Zasshi, 122, 413 - 417 (2002).

13) Aimoto S., "Encyclopedia of Experimental Chemistry," 4th ed., Vol. 22, ed. by Iguchi H., The Chemical Society of Japan, Maruzen Co., Ltd., Tokyo, 1991, p. 261.

14) Addition of $\mathbf{2 a}(1 \mathrm{eq})$ to $10 \mathrm{~mm}$ solution of $\mathbf{1}$ in $\mathrm{CDCl}_{3}$ caused the following downfield shifts $(\Delta \delta \mathrm{ppm})$ : $\mathrm{OHs}(0.80 \mathrm{ppm})$ for $\mathbf{1 a}-\mathbf{2 a}$; NHs (0.65 ppm) for $\mathbf{1 b}-\mathbf{2 a}$.

15) Ogoshi H., Hayashi T., "Encyclopedia of Experimental Chemistry," 4th ed., Vol. 27, ed. by Iguchi H., The Chemical Society of Japan, Maruzen Co., Ltd., Tokyo, 1991, pp. 19-25.

16) Hirose K., J. Inc. Phenom. Macrocycl. Chem., 39, 193-209 (2001).

17) We were unable to accurately determine $K_{\mathrm{a}}$ values using $\mathrm{OH}$ or $\mathrm{NH}$ protons of peptides because of the extensive broadening of these signals during titration. 